\title{
Construction of Quality Assurance System for Postgraduate Education in Local Colleges and Universities under the Background of "Double First Class"
}

\author{
Li Bo \\ Graduate School, Jilin Agricultural University, Changchun, China \\ 83574736@qq.com
}

Keywords: "Double first class" construction; dissertation citation; quality assurance system

\begin{abstract}
In recent years, postgraduate education has been mentioned at an unprecedented level. By improving the quality of dissertations as the starting point, this paper explores the inherent law of cultivating excellent graduate students, optimizes the layout of disciplines scientifically, and constructs the quality assurance system of graduate education in local colleges and universities.
\end{abstract}

\section{Introduction}

As the top of national education, postgraduate education undertakes the dual mission of "high-end talent supply" and "scientific and technological innovation", and is an important combination of the strategy of rejuvenating the country through science and education and strengthening the country with talents. Undoubtedly, after more than 30 years of continuous exploration and practice, China's graduate education has made remarkable achievements, has become a major country with global influence in graduate education, but there is still a big gap compared with the international first-class education level. Therefore, we must base on the overall situation of modernization construction, systematically plan the comprehensive reform and development of postgraduate education from a strategic height, and promote our country from a big country of postgraduate education to an educational power.

In October 2015, the State Council issued the "Overall Plan for Promoting the Construction of First-class Universities and Disciplines in the World" (hereinafter referred to as "double first-class" construction), which is an important strategic decision made by the Party Central Committee and the State Council in the new historical period to enhance the development level of higher education and build a powerful country in higher education. In his speech at the 33rd meeting of the Academic Degree Committee of the State Council, the then Vice Premier of the State Council, Comrade Liu Yandong, further pointed out that first-class postgraduate education is an important part of the "two-class" construction, and it is bound to promote the comprehensive strength of postgraduate education. Looking at the world-renowned first-class universities, all of them have the first-class postgraduate training strength, and all of them take the training of first-class postgraduates as an important symbol. "Double first-class" construction in policy and funding to give precise support to the construction of first-class universities to drive the overall development, first-class discipline construction to drive key breakthroughs.

\section{Development of Postgraduate Education}

On January 17, 2017, the Ministry of Education and the Academic Degrees Committee of the State Council officially issued the "Thirteenth Five-Year Plan" for the Development of Degree and Graduate Education, which states that since the resumption of graduate education in China, after decades of development, a relatively complete system of graduate and graduate education has been established to ensure graduate education. The basic quality of education has basically achieved the strategic goal of fostering high-level talents independently. Especially since the 18th National Congress of the Communist Party of China, the reform of postgraduate education has been deepened in an all-round way, the main line of development of "service demand and improvement 
of quality" has been established, new breakthroughs have been made in the reform of training mode, the awareness of quality and the level of development have been significantly improved, the structural optimization and adjustment have made remarkable progress, the guarantee of investment has been improved, and the autonomy of running A number of high-level universities and disciplines have risen rapidly and their international influence has been continuously enhanced, which has laid a good foundation for the innovation and development of degree and postgraduate education during the 13th Five-Year Plan period.

According to the statistics released by the Ministry of Education, there are 575 colleges and universities responsible for the cultivation of Postgraduates in the overall layout of higher education in China, of which about 2/3 are local colleges and universities. This shows that local colleges and universities are already the main units undertaking postgraduate education. How to seize the great opportunity of "double-first-class" construction and explore the construction of a first-class postgraduate education quality assurance system with local characteristics and unique advantages is a brand-new topic for every postgraduate educator in local colleges and universities.

In view of the realistic needs of the development of postgraduate education and the new requirements of social, economic, scientific, technological and cultural development for the quality of postgraduate education under the current situation, this paper, based on the current situation of postgraduate education in local colleges and universities, takes the citation of postgraduate dissertations in China KnowledgeNet electronic database as the breakthrough point. This paper explores the discipline laws of high citation frequency papers, and establishes and improves the quality assurance system of first-class postgraduate education on the basis of rational understanding and effective use of these laws.

\section{Citation of Dissertations}

The quality evaluation and influence of dissertations can be reflected by their quoted frequency. Higher quality papers get higher citation frequencies, whereas less quality dissertations are cited. Through statistical analysis of the citation frequency of the papers, it can objectively reflect the academic influence of the papers of each training unit. Academic influence is closely related to the quality and dissemination of the papers. By counting the citation frequency of the papers of each university, the overall quality of the papers can be reflected, providing useful objective reference data for the quality of graduate training. Taking Jilin Province as an example, the frequency of downloading and citing postgraduate papers of Jilin University and Northeast Normal University is obviously better than that of other universities. It shows that the academic influence and dissemination scope of the dissertations written by key universities such as 985 and 211 are indeed higher than those produced by ordinary universities. The high citation data of dissertations can objectively reflect the quality of education and teaching in different colleges and universities, which conforms to the training objectives and quality orientation of colleges and universities at different levels.

On the other hand, the advantage and characteristic discipline of universities is the external factor that breeds excellent dissertations. After years of discipline development and academic precipitation, different levels of colleges and universities have accurately positioned their objectives, integrated high-quality school-running resources, strengthened discipline advantages, developed characteristic majors, gradually formed brand effect, constructed "academic authority", and conducted scientific research on high-level academic platforms by graduate students, which is bound to form endogenous impetus. It is easy to produce high-quality dissertations. Taking Jilin Agricultural University as an example, $5 \%$ and $20 \%$ of the highly cited dissertations of our graduate students are mainly concentrated in agriculture, engineering and medicine, which are characteristic disciplines of school-running development. The corresponding disciplines of crop science, food science and engineering, and traditional Chinese medicine are key national cultivation, key provincial and ministerial disciplines. Jilin Province attaches great importance to the development of disciplines, distinctive disciplinary characteristics and training advantages for the cultivation of outstanding personnel to provide a good external environment. 
To build up a good external environment and recruit high-quality students, we should have a good guidance from famous teachers. Postgraduate tutors and professors should be a demonstration group. Their superb academic level, strong working ability and rich personality charm will have an important impact on the majority of students. Excellent tutors play a vital role in the cultivation of Postgraduates' professional quality and the improvement of their knowledge structure.

\section{Construction of quality assurance system for graduate education}

\subsection{Strengthening the construction of key disciplines based on Characteristics}

The country has started the construction of "double first-class" in an all-round way. Universities at different levels should take this opportunity to re-plan their own development orientation. Effective use of such effective means as dynamic adjustment of academic degree points to foster their own development advantages, intensify the construction of characteristic disciplines, refine the dominant disciplines, support the support of potential disciplines, strengthen the potential disciplines, constantly optimize the structure and layout of the school disciplines, and train outstanding talents and high-level students Results output builds a good external environment.

\subsection{Clear responsibilities and inspiring the main body of Education}

High quality tutors team is an important factor determining the quality of postgraduate training. Whether from the top-level design of the school or to the construction of the management system, the teaching concept of building a high-quality tutor team has penetrated into all levels of the school. At the school level, we should pay attention to training and introducing a large number of teachers with high academic and professional qualities. At the same time, we should formulate a series of management systems which are conducive to improving the professional level of teachers, encouraging them to keep forging ahead and strive for becoming famous teachers, increase support and support, and let famous teachers play a leading and radiating role in the whole school. Let more teachers enter the ranks of famous teachers. At the management level, we should establish and perfect the system documents, innovate the management system of graduate tutors, introduce a good competition mechanism, implement the dynamic management of tutors, set up a four-level management platform of "school-college-subject-tutor", gradually build the tutor responsible for the discipline and the discipline responsible for the college. Colleges are responsible for the school's work system, clear responsibilities and division of labor, refine the responsibilities and requirements of education, to achieve layers of supervision, layers of responsibility. Efforts should be made to create high-quality, high level and high quality "three high" mentors. At the level of tutors themselves, they should constantly enrich their academic level and practical experience, enhance their professional quality and innovative ability, establish an interactive exchange platform with postgraduates, preside over and lead postgraduates to participate in research projects, promote the construction of research teams, encourage postgraduates to develop independently and strive for excellence.

\subsection{Classification training, tracking and training outstanding talents}

Unlike graduate education, postgraduates should focus on "professional research" and "process training." The first is professional research. The purpose of postgraduate teaching is different from the basic knowledge education of undergraduate specialty, which is an extension of a certain professional field. On the one hand, the teaching content of the school should be leading, forward-looking and professional, to ensure that graduate students can be exposed to the cutting-edge knowledge of the subject. On the other hand, schools should vigorously support graduate students to participate in high-level scientific research, scientific research is the academic starting point of graduate education, is the basic provisions of graduate teaching activities, only in strict academic training to train outstanding talents, and thus promote high-level academic output. High-quality graduate training and high-level scientific research are interdependent and mutually reinforcing. The quality of graduate training plays a very important role in the scientific research 
level and academic influence dissemination of a university, weakening either side will affect the other side. The two is process training. Postgraduate education is a "input-output" system process, which requires a clear training objectives, standardized training process, but also refine the learning tasks and objectives at all stages to ensure the quality of output. Management departments should formulate rules and regulations scientifically to ensure that the key nodes to improve the quality of papers, namely, the role of the source of the report, the role of mid-term assessment checks, the role of paper review and supervision, the role of paper defense checkpoints, the planned phased implementation of the graduate training program.

\section{Conclusion}

Deepening the reform has become the main tone of the development of postgraduate education. Grasping the connotation to promote the quality has increasingly become the main theme of the development of postgraduate education. Serving the economic and social needs has increasingly become the main direction of the development of postgraduate education. Graduate education has entered the era of quality development. Graduate students'academic achievements will also receive more and more extensive attention and have an important academic impact. The road to development is still facing arduous tasks and challenges. This requires every graduate educator to make great efforts to create a stable, progressive and new graduate education.

\section{References}

[1] The State Council shall co-ordinate the overall plan for the construction of world class universities and first-class disciplines. [2015] No.64,2015.10

[2] Liu Yandong, speaking at the thirty-third meeting of the Academic Degrees Committee of the State Council.

[3] QiuHongbin. Establish a scientific quality concept and establish a quality assurance system for postgraduate education in local universities [J].Degree and postgraduate education, 2012, (5), 5-8

[4] Zhang Yanguo, Liu Xiaoqiang. Reflections on the Quality Construction of Graduate Education in China [J].Degree and Graduate Education, 2012, (5), 5-8

[5] Chen Xu. Clear Orientation, Strengthen Assessment, Deepen Reform and Improve Quality [J].Degree and Graduate Education, 2015, (1), 18-19 